\title{
Play in Childhood: Introduction to the Special Issue
}

\author{
ZHANG Heyi | ORCID : 0000-0002-6625-6960 \\ Assistant Professor, Institute (Department) of Early Childhood Education, \\ Beijing Normal University, Beijng, PR China \\ heyizhang@bnu.edu.cn
}

It is a great honor and pleasure for me to serve as the guest editor for this special issue on "Play in Childhood", strongly supported by Professor Michael A. Peters and Professor Zhu Xudong, the editors-in-chief of Beijing International Review of Education. My interests in play started from the very beginning of my $\mathrm{PhD}$ journey at the University of Cambridge, where I was exposed to a wide range of research on the role of play in child development and learning. In recent years, there is a considerable body of research exploring children's play in the fields of developmental psychology, early childhood education, anthropology, neuroscience, etc. It has been increasingly recognised within academia, early childhood settings, and policy communities that the provision of play opportunities is vital to children's physical, cognitive, emotional and social development. At the same time, however, there are many challenges related to understanding and supporting high-quality play.

We therefore planned this issue to reflect the importance of play in childhood, and more importantly, to generate insights and implications to improve the quality of play experiences for children. We issued the following Call for Papers:

\section{Play in Childhood}

There is strong and consistent evidence that play influences children's learning and development. Within the educational field, the value of play has been increasingly recognised by academics, educational practitioners, and policymakers worldwide. Play is strongly associated with children's cognitive and social-emotional development, preparing children for academic achievement and lifelong success. Through play, children observe, regulate, and restrain themselves, thereby mastering various skills and acquiring an awareness of limits. However, some parents and early years teachers may have doubts about the role of play in child development and learning, challenging that play-based 
learning in kindergartens may fail to prepare children for the transition from preschool to primary school. Questions arise such as how to meet the learning needs and goals of young children through high-quality play-based activities. Furthermore, compared to what we know about play in early childhood, scant research has examined play in middle childhood. Although play is predominant in early childhood, it persists into middle childhood. Therefore, it is important to understand the role of play in child outcomes within and beyond early childhood.

We formulated the title of this special issue as simple and broad as "Play in Childhood" to encourage contributions from different contexts and through different perspectives. This special issue is motivated by a desire to provide a platform for researchers who aim to explore and exchange ideas about play, which will be important for practitioners interested in optimising play experiences of children. This special issue contains seven theoretical and empirical papers. Three common themes appear across the papers: 1. play and learning; 2. play and culture; 3 . play in middle childhood. All together, the three themes allow us to better understand the nature and value of children's play, and the extent and quality of current practices.

According to a comprehensive report on the value of child play (Whitebread, 2012), the existing literature is predominantly concerned with four main topics, including the definition of play and its distinction from other activities, the benefits of play, play and the curriculum, and the role of adults in children's play. When exploring the four topics, many researchers have discussed the relation between play and learning. For instance, there are different views in research that conceptualises play. In some work, play is defined as an educationally powerful process during which learning will occur spontaneously, while others have argued that this view may oversimplify the variety and complexity of play and its connections with learning (Yelland, 2011). Instead of simply stating that children learn through play, it is necessary to understand what kind of learning may occur in play and how learning is promoted by specific playful activities. A study investigating young children's own understanding of play and learning has indicated the importance of engaging children to reflect learning that occurred in their playful activities, which may avoid the dichotomy of play and learning (Theobald et al., 2015). Seeking a sophisticated and professional understanding of play and learning is being valued increasingly in early childhood education settings, as it will enable practitioners to enhance 
curriculum development and pedagogical practices to support children's optimal development.

In this special issue, the first three articles are related to the link between play and learning, but with different foci. In the article titled "Play and Learning? A Critical Discourse Analysis of the Treatment of Play in Relation to Learning in Australian and New Zealand Early Childhood Curricula Frameworks" by Fiona Westbrook and Elise Hunkin, play is viewed as an activator of learning, which finds support in early childhood curricula in both New Zealand and Australia. The authors have also highlighted the importance of children being active agents in their play and learning processes. Also, E. Jayne White's article, "Visual Surplus of Seeing Play in ECE: Beyond the Ontologic Trap?", has provided inspiring arguments concerning the need for teachers to unleash learning in play beyond the constraints of established curriculum ideals. The use of a 360 degree camera to track children's behaviour in spontaneous play activities allows teachers to observe and understand the authenticity of child play and its learning potential rather than frame play to match the curriculum. In line with the article focusing on visual surplus, Rene Novak has discussed problems caused by framing play in curriculum documents in "The Paradox of Contemporary Play: The Dangers of Framing Play". The author has argued that framing play as a tool for teaching may erode authentic play, which calls for more clear phenomenological and methodological investigations into the nature of play.

\section{$2 \quad$ Play and Culture}

There is growing evidence that play is culturally contextualised. There are cultural variations in children's play activities. Taking cultural factors into account enables researchers and practitioners to achieve a profound understanding of not only cultural values about play in childhood but also the benefits of engaging children in culturally responsive educational experiences. Exploring and learning about culture occurs from the very beginning of a child's life, contributing to the development of self-esteem, cultural identities, and awareness and appreciation of diverse cultures. Existing studies on play and culture have shown that compared to broader sociocultural influences such as the impact of social class, specific practices in home and early years settings are more directly related to children's outcomes (Whitebread \& Basilio, 2013). This view has received further support in our special issue that includes research regarding play practices in different cultural contexts.

The next three articles in this special issue have applied a cultural lens to shed light on the significance of play in childhood. Two contributions are 
concerned with the role of play in children's development of cultural identities. The article by Sonja Arndt, "Rethinking Play, Diversity and Belonging in Early Childhood Education”, has argued for a reconceptualisation of children's play as an ongoing process of forming a sense of belonging, which is interrelated with children's cultural identities. Through playful explorations, children are intrinsically motivated to make sense of their world and learn about their own cultural identity and the differences between cultures. The author has also pointed out the need for teachers to incorporate cultural diversity into pedagogical practices in early childhood education. Also, the authors Pui et al. have generated consistent empirical evidence in their article titled "Developing Children's Cultural Identities Through Play". Qualitative findings suggested how a play-based setting containing rich cultural elements in a Chinese kindergarten contributed to children's cultural identities and developmental outcomes in general. Additional discussions concerning play and culture can be found in Aleksandra Acker's "Can We Have More Hand-Drums? Preschool Children's Musical Play in a Program Exploring Diverse Languages". This work illustrated children's active involvement in a culturally diverse music program using the Learning Stories approach. The concrete examples described in this work may inspire teachers to reflect upon cultural diversity in early years classrooms.

\section{3}

\section{Play in Middle Childhood}

Compared to abundant research evidence showing the importance of play in early childhood, play in middle childhood has often been ignored. Examining children's play experiences in middle childhood will allow us to better understand the continuous contribution of play to developmental outcomes. Limited research has suggested that play remains important to children's wellbeing beyond the early years. For instance, Goldstein and Winnier (2011) provided preliminary evidence that the engagement of 8-to 11-year-olds in role play, pretense, and acting classes predicted theory of mind skills, which is consistent with findings regarding younger children. When practicing pretense, children are more able to be patient and perseverant (Singer \& Singer, 2006), and have rich opportunities to self-regulate and collaborate with others (Bergen \& Fromberg, 2009). Such practice enables children to understand others' beliefs and intentions as well as develop their own executive function and selfregulation skills, thereby contributing to their long-term cognitive, social, and emotional development.

Understanding children's own perceptions of their play can guide practice and policy to improve the quality of provision. Some existing studies on play in 
middle childhood have relied on parents' reports of their children's play activities, which may not be as reliable as children's own perspectives on play. Howard et al. (2017) have revealed the importance of listening to children when studying play in middle childhood, suggesting that play is essential for 7- to 11year-olds. Children's discussions of play highlight the benefits of play for their social competence, which is consistent with Erikson's (1950) viewpoint regarding the link between play and social development in middle childhood. Play also has great emotional importance for children. Children in this study, for instance, reported positive feelings related to play and negative emotions when not allowed to play. The continuous benefits of play in middle childhood are further discussed in the current special issue.

In this special issue, we have an article titled "Features of Social Play in 8- to 11-Year-Olds in China: Exploring Children's Own Perspectives" by Rao Zhen and Jenny Gibson. The authors examined children's perspectives and feelings related to social play and revealed the continued popularity and significance of pretend play in middle childhood in the Chinese context, which is in line with limited existing findings in Western cultures (e.g. Bergen \& Fromberg, 2009; Howard et al., 2017). The empirical evidence has generated valuable implications for researchers, practitioners, and policymakers, who need to advocate adequate play opportunities in middle childhood to support children's longterm development.

What emerges from the present special issue is that, while there are many challenges and limits regarding play in terms of conceptualisation and practice, the articles have yielded directions for future research and practice. We hope this special issue will expand the knowledge base that supports the influential role of play in childhood and children's healthy development.

\section{References}

Bergen, D., \& Fromberg, D. P. (2009). Play and Social Interaction in Middle Childhood. Phi Delta Kappan, 9o(6), 426-430.

Erikson, E. H. (1950). Childhood and Society. Norton.

Goldstein, T. R., \& Winner, E. (2011). Engagement in Role Play, Pretense, and Acting Classes Predict Advanced Theory of Mind Skill in Middle Childhood. Imagination, Cognition and Personality, 3o(3), 249-258.

Howard, J., Miles, G. E., Rees-Davies, L., \& Bertenshaw, E. J. (2017). Play in Middle Childhood: Everyday play behaviour and associated emotions. Children \& Society, ${ }^{17(5),}$ $378-389$. 
Singer, D. G., \& Singer, J. L. (2015). Fantasy and Imagination. In D. P. Fromberg \& D. Bergen (Eds.). Play from Birth to Twelve: Contexts, Perspectives, and Meanings. (2nd ed., pp. 271-278). Routledge.

Theobald, M., Danby, S., Einarsdóttir, J., Bourne, J., Jones, D., Ross, S., \& Carter-Jones, C. (2015). Children's Perspectives of Play and Learning for Educational Practice. Education Sciences, 5(4), 345-362.

Whitebread, D. (2012). The Importance of play: A report on the value of children's play with a series of policy recommendations. Waldorf Resources. https://www.waldorfresources.org/fileadmin/files/pictures/Early_Childhood/dr_david_whitebread_-_ the_importance_of_play.pdf.

Whitebread, D., \& Basilio, M. (2013). Play, Culture and Creativity. Cultures of Creativity. The LEGO Foundation. https://www.educ.cam.ac.uk/images/pedal/play-culturearticle.pdf.

Yelland, N. (2011). Reconceptualising Play and Learning in the Lives of Young Children. Australasian Journal of Early Childhood, 36(2), 4-12. 